\title{
Local Abnormalities in Coagulation and Fibrinolytic Pathways Predispose to Alveolar Fibrin Deposition in the Adult Respiratory Distress Syndrome
}

\author{
Steven Idell, ${ }^{\star}$ Kathleen K. James," Eugene G. Levin," Bradford S. Schwartz, Naveen Manchanda," Richard J. Maunder," \\ Thomas R. Martin," Jerry McLarty," and Daryl S. Fair* \\ ${ }^{*}$ Departments of Medicine and Biochemistry, The University of Texas Health Center at Tyler, Tyler, Texas 75710; ${ }^{\ddagger}$ Department of \\ Basic and Clinical Research, Institute of Scripps Clinic, La Jolla, California 92037; \$Department of Medicine, University of Wisconsin, \\ Madison, Wisconsin 53706; and"Veterans Administration Hospital, Seattle, Washington 98108
}

\begin{abstract}
To determine the possible mechanism(s) promoting alveolar fibrin deposition in the adult respiratory distress syndrome (ARDS), we investigated the initiation and regulation of both fibrinolysis and coagulation from patients with ARDS ( $n$ $=14)$, at risk for ARDS ( $n=5)$, and with interstitial lung diseases (ILD) $(n=8)$, and normal healthy individuals ( $n$ = 13). Bronchoalveolar lavage (BAL) extrinsic pathway inhibitor activity was increased in ARDS BAL compared with patients at risk for ARDS $(P=0.0146)$ or normal controls $(P$ $=0.0013)$ but tissue factor-factor VII procoagulant activity was significantly increased in ARDS BAL compared with all other groups $(P<0.001)$. Fibrinolytic activity was not detectable in BAL of 10 of the 14 patients with ARDS and low levels of activity were found in BAL of the other four ARDS patients. Depressed fibrinolysis in ARDS BAL was not due to local insufficiency of plasminogen; rather, there was inhibition of both plasmin and plasminogen activator. Plasminogen activator inhibitor 1 was variably detected and low levels of plasminogen activator inhibitor 2 were found in two ARDS BAL samples, but plasminogen activator inhibitor 2 was otherwise undetectable. ARDS BAL antiplasmin activity was, in part, due to $\alpha_{2}$-antiplasmin. We conclude that abnormalities that result in enhanced coagulation and depressed fibrinolysis, thereby predisposing to alveolar fibrin deposition, occur in the alveolar lining fluids from patients with ARDS.
\end{abstract}

\section{Introduction}

Alveolar fibrin deposition commonly accompanies human lung injuries such as pneumonitis and the interstitial lung diseases $(1,2)$ and is especially prominent in the adult respiratory distress syndrome (ARDS) ${ }^{1}$ (3). The importance of alveolar

\footnotetext{
Address reprint requests to Dr. Idell, University of Texas Health Center, P.O. Box 2003, Tyler, TX 75710. 1989.

Received for publication $12 \mathrm{July} 1988$ and in revised form $13 \mathrm{March}$
}

1. Abbreviations used in this paper: $\alpha_{2} \mathrm{AP}, \alpha_{2}$-antiplasmin; ARDS, adult respiratory distress syndrome; AT III, antithrombin III; BAL, bronchoalveolar lavage; EPI, extrinsic pathway inhibitor; ILD, interstitial lung disease; PA, plasminogen activator; PAI-1 and PAI-2, plasminogen activator inhibitors 1 and 2; PEEP, positive end-expiratory pressure; u-PA, urokinase.

J. Clin. Invest.

(c) The American Society for Clinical Investigation, Inc.

$0021-9738 / 89 / 08 / 0695 / 11 \quad \$ 2.00$

Volume 84, August 1989, 695-705 fibrin deposition in the pathogenesis of pulmonary inflammation is currently unclear, but circumstantial evidence suggests the likelihood of an important role. Coagulation and extravascular fibrin may liberate cleavage products which are capable of potentiating the acute inflammatory response via effects on chemotaxis, vascular permeability, and immunomodulation (4-9). Activation of coagulation or fibrinolysis may, in turn, activate complement $(10,11)$, kinin-forming pathways (12), and release of neutrophil elastase $(12,13)$. In addition, fibrin deposits may influence the reparative response to acute lung injury. For example, inflammatory cells, including fibroblasts and macrophages, may aggregate upon fibrin matrices $(14,15)$ which may promote collagen deposition in vitro (16). Persistent fibrin deposits may occur in areas of pulmonary scarring $(17,18)$, further supporting the role of fibrin in pulmonary fibrosis. Studies of patients with ARDS and of experimental animals have further shown that extravascular, in particular, alveolar fibrin occurs in lung tissue in which fibrotic repair results after acute injury $(1,3,19,20)$. These observations suggest that extravascular fibrin and disordered pathways of fibrin turnover may play an important role in the pathogenesis of both acute lung injury and repair. Delineation of local abnormalities that promote alveolar fibrin deposition is therefore germane to understanding the pathogenesis of ARDS.

Abnormalities in the pathways of fibrin turnover occur in alveolar lining fluids in association with lung diseases in humans and pneumonitis in experimental animals (19-23). Cells harvested from bronchoalveolar lavage (BAL) of patients with interstitial inflammation due to idiopathic pulmonary fibrosis and sarcoidosis have increased procoagulant activity and decreased fibrinolytic activity when compared with normal healthy controls (23). In rabbits treated with phorbal myristate acetate, increased BAL fibrinolytic activity was found to correlate with the clearance of alveolar fibrin from the injured lung (2). We have shown that increased procoagulant activity occurs in the BAL of patients with ARDS (21) and marmosets with bleomycin-induced lung injury in which prominent alveolar fibrin deposition occurred (19). These studies suggest that abnormalities of coagulation and/or fibrinolysis which occur in alveolar lining fluids may influence fibrin deposition associated with alveolar inflammation. In this study, we document the concomitant increase in coagulation with a decrease in fibrinolysis in the alveolar fluids of patients with ARDS and characterize the mechanisms responsible for the observed abnormalities of fibrin turnover.

\section{Methods}

Patients. BAL fluids from 40 patients were studied; 14 patients had ARDS, 5 were at risk for ARDS, 8 had interstitial lung diseases (ILD), 
and 13 were normal healthy control subjects with no evidence of pulmonary disease. Of patients at risk for ARDS, two went on to develop the syndrome, were studied after ARDS had developed, and were included in the ARDS group. Bronchoscopy and BAL were performed after informed consent was obtained from each subject or nearest relative. The study protocol was approved by the Institutional Review Board of the Veterans Administration Medical Center, Seattle, WA. Criteria for patient selection and clinical characteristics of these groups are given in the subsections below.

$A R D S$. All patients were studied within $3 \mathrm{~d}$ of recognition of ARDS. Patients ranged in age from 19 to 84 yr. Five patients had underlying sepsis; the remainder had other underlying conditions that included aspiration pneumonitis, multiple trauma, and drug overdose. All of the patients with ARDS were mechanically ventilated while the BAL procedure was performed and in no case did the patient appear to be adversely affected by the procedure. ARDS was defined as the sudden onset of respiratory failure associated with refractory hypoxemia, and arterial $\mathrm{PO}_{2}$ of $\leq 60$ with a fractional inspired oxygen $\left(\mathrm{F}_{i} \mathrm{O}_{2}\right)$ of $\geq 60 \%$ and widespread diffuse infiltrates over the lungs on chest $\mathrm{x}$-ray $(21,22)$. Pulmonary capillary wedge pressure was measured after placement of a Swan-Ganz catheter and was $<18 \mathrm{~mm} \mathrm{Hg}$ in all cases. Clinical data for patients with ARDS and those at risk for ARDS are shown in Table I.

Patients at risk for ARDS. Five patients who were considered to be at risk for ARDS, by virtue of having underlying multiple trauma with extensive tissue injury, were studied. All of these patients were being mechanically ventilated at the time of the BAL procedure and three were being hemodynamically monitored. Two of these patients (Nos. 7 and 13) were initially in the at-risk group but later went on to fulfill criteria for ARDS by the time of BAL. The other five patients did not develop ARDS (Table I).

Analysis of the severity of illness of patients with ARDS and at risk for ARDS. The severity of illness of patients with ARDS at the time of BAL was assessed using several different scoring systems. Oxygenation and radiographic and compliance scores were developed according to the classification systems developed by Weinberg and colleagues (24) and a composite severity score was then developed based on these analyses. The radiographic score of the severity of pulmonary infiltrates was tabulated as previously reported by Weinberg et al. (24). In addition, an oxygenation score, or $\mathrm{PaO}_{2} / \mathrm{F}_{\mathrm{i}} \mathrm{O}_{2}$ ratio $(\mathrm{P} / \mathrm{F})$, was determined (24), where $\mathrm{F}_{\mathrm{i}} \mathrm{O}_{2}=$ fractional concentration of inspired oxygen and $\mathrm{PaO}_{2}=$ partial pressure of oxygen in arterial blood. The following weighted score was used to quantitate the abnormality in gas exchange or $O_{2}$ score: $0, \mathrm{P} / \mathrm{F}>265 ; 1, \mathrm{P} / \mathrm{F}=200-264 ; 2, \mathrm{P} / \mathrm{F}=135-199 ; 3, \mathrm{P} / \mathrm{F}$ $=70-134 ; 4, \mathrm{P} / \mathrm{F}<70$. If the $\mathrm{PaO}_{2} / \mathrm{F}_{\mathrm{i}} \mathrm{O}_{2}$ ratio was measured during positive end-expiratory pressure (PEEP) therapy (PEEP $\left.>10 \mathrm{~cm} \mathrm{H}_{2} \mathrm{O}\right)$, one point was added to the gas exchange score (up to a maximum of 4 ). Selected parameters, including the mean pulmonary artery pressure, pulmonary artery wedge pressure, and bedside lung compliance (data not shown) were also determined immediately before BAL in patients with ARDS. A respiratory system compliance score was calculated in patients receiving mechanical ventilation as the corrected tidal volume

Table I. Clinical Data for Patients with ARDS and Those at Risk for ARDS

\begin{tabular}{|c|c|c|c|c|c|c|c|c|c|c|c|c|}
\hline $\begin{array}{l}\text { Patient } \\
\text { No. }\end{array}$ & Age & $\begin{array}{l}\text { Clinical } \\
\text { risks }\end{array}$ & $\begin{array}{l}\text { Clinical } \\
\text { outcome }\end{array}$ & PEEP & $\mathrm{P} / \mathrm{F}$ & $F_{\mathrm{i}} \mathrm{O}_{2}$ & $\mathrm{PO}_{2}$ & PAP & $\begin{array}{l}\text { Chest } \\
\text { x-ray } \\
\text { score }\end{array}$ & $\begin{array}{c}\mathrm{O}_{2} \\
\text { score }\end{array}$ & $\begin{array}{l}\text { Severity } \\
\text { score }\end{array}$ & $\begin{array}{l}\text { Compliance } \\
\text { score }\end{array}$ \\
\hline \multicolumn{13}{|l|}{ ARDS } \\
\hline 1 & 28 & OD/Asp & D & 5 & 211.1 & 0.45 & 95 & 16 & 2 & 1 & 2.00 & 0 \\
\hline 2 & 43 & Spinal Fx/? & A & 0 & 113.3 & 0.6 & 68 & - & 2.7 & 4 & 3.23 & 3 \\
\hline 3 & 51 & Sepsis & A & 15 & 152.5 & 0.8 & 122 & 23 & 2 & 3 & 1.70 & 0 \\
\hline 4 & 29 & Sepsis & A & 15 & 204.0 & 0.5 & 102 & 30 & 2.5 & 2 & 2.50 & 3 \\
\hline 5 & 46 & OD/Asp & D & 20 & 212.7 & 0.6 & 73 & 26 & 2.9 & 4 & 3.45 & - \\
\hline 6 & 20 & MT & $\mathrm{D}$ & 10 & 95.0 & 0.8 & 76 & - & 3.2 & 4 & 3.60 & - \\
\hline 7 & 58 & Sepsis & A & 10 & 202.5 & 0.4 & 81 & 26 & 1.8 & 2 & 2.30 & 3 \\
\hline 8 & 48 & Sepsis/Asp & A & 5 & 143.3 & 0.6 & 86 & 38 & 2.8 & 2 & 2.60 & 3 \\
\hline 9 & 31 & MT & A & 10 & 170.0 & 0.4 & 68 & 48 & 2.9 & 3 & 2.63 & 2 \\
\hline 10 & 19 & MT & $\mathrm{D}$ & 15 & 144.0 & 0.5 & 72 & 36 & 3.6 & 3 & 3.30 & - \\
\hline 11 & 25 & MT & A & 5 & 127.1 & 0.7 & 89 & 16 & - & 3 & 2.00 & 1 \\
\hline 12 & 43 & MT & A & 15 & 172.5 & 0.4 & 69 & 33 & 2.3 & 3 & 2.10 & 1 \\
\hline 13 & 44 & OD & A & 10 & 340.0 & 0.4 & 136 & 18 & 1 & 1 & 0.67 & 0 \\
\hline 14 & 60 & Sepsis/Trans & $\mathrm{D}$ & 10 & 162.0 & 0.5 & 81 & 40 & 2.6 & 3 & 2.53 & 2 \\
\hline Mean & 38.9 & & & 10.4 & 168.5 & 0.55 & 87.0 & 29.2 & 2.49 & 2.71 & 2.47 & 1.9 \\
\hline SD & 13.5 & & & 5.4 & 60.5 & 0.14 & 10.2 & 20.7 & 0.67 & 0.99 & 0.78 & 1.2 \\
\hline \multicolumn{13}{|l|}{ At risk } \\
\hline 15 & 36 & MT & D & 0 & 49.0 & 0.60 & 294 & - & 0 & 0 & 0 & - \\
\hline 16 & 51 & MT & $\mathrm{D}$ & 0 & 418.0 & 1.00 & 418 & 30 & 2.2 & 0 & 1.7 & 3 \\
\hline 17 & 37 & $\mathbf{M T}$ & A & 0 & 190.0 & 0.50 & 95 & - & 1.3 & 2 & 1.4 & 1 \\
\hline 18 & 60 & MT & A & 5 & 178.0 & 0.50 & 89 & - & 1.1 & 2 & 1 & 0 \\
\hline 19 & $\underline{21}$ & MT & A & 0 & 314.3 & 0.35 & 110 & 11 & 1.3 & $\underline{0}$ & 1.4 & 3 \\
\hline Mean & 37.7 & & & & 229.9 & 0.59 & 201.2 & & 1.02 & 0.68 & 1.03 & 1.8 \\
\hline \multirow[t]{2}{*}{ SD } & 15.7 & & & & 126.1 & 0.22 & 132.5 & & 0.81 & 1.03 & 0.62 & 1.3 \\
\hline & \multicolumn{3}{|c|}{$P$ vs. ARDS } & 0.0030 & 0.0083 & 0.7685 & 0.0132 & & 0.0049 & 0.0030 & 0.0026 & 0.86 \\
\hline
\end{tabular}

Abbreviations: OD, drug overdose; Asp, aspiration; $\mathrm{Fx}$, fracture; $\mathrm{MT}$, multiple trauma; Trans, transfusion; $\mathrm{P} / \mathrm{F}$, ratio of $\mathrm{PO}_{2} / \mathrm{F}_{i} \mathrm{O}_{2}$ where $\mathrm{PO}{ }_{2}$ is the partial pressure of arterial oxygen determined immediately before $\mathrm{BAL}$, and $\mathrm{F}_{\mathrm{i}} \mathrm{O}_{2}$ is fractional concentration of inspired oxygen; PEEP, positive end expiratory pressure; PAP, mean pulmonary artery pressure; $\mathrm{D}$, dead; $\mathrm{A}$, alive. Chest $\mathrm{x}$-ray, $\mathrm{O}_{2}$, and severity scores were used as indexes of physiologic impairment as described in the text. 
divided by the static airway pressure at end inspiration (after subtracting PEEP). A weighted score was then used to quantitate the severity of compliance alterations in patients with ARDS: $0, \mathrm{C}_{\mathrm{ST}}>50 \mathrm{ml} / \mathrm{cm}$ $\mathrm{H}_{2} \mathrm{O} ; 1, \mathrm{C}_{\mathrm{ST}}=40-49 ; 2, \mathrm{C}_{\mathrm{ST}}=30-39 ; 3, \mathrm{C}_{\mathrm{ST}}=20-29 ; 4, \mathrm{C}_{\mathrm{ST}}<20$. Scores determined for each of the individual components; the radiographic, $\mathrm{O}_{2}$, and compliance scores were then averaged to create the composite lung injury severity score (25).

Patients with ILD. Of the eight patients with ILD studied, five had idiopathic pulmonary fibrosis with long-standing ( $>1 \mathrm{yr}$ ) infiltrates on chest $\mathrm{x}$-ray and/or restrictive abnormalities on pulmonary function testing. Three of these patients had open lung biopsies with confirmation of the diagnosis. Two patients had pulmonary fibrosis with underlying rheumatoid arthritis or polymyositis. In both cases, the diagnosis of ILD was confirmed by open lung biopsy. In one case, pulmonary interstitial disease was radiographically apparent and felt to represent fibrosis and long-standing congestive heart failure associated with documented pulmonary arterial hypertension preceding mitral valve replacement.

Normal control subjects. 13 young, healthy individuals with no known pulmonary disease served as normal controls. All of these subjects were nonsmokers with an age range of 21-30 yr.

$B A L$ samples and preparation. BAL was performed and processed as previously described (21). The lavage procedure was well tolerated in all patient groups with recovery of $\sim 50 \%$ of the instilled fluid (coefficient of variation equals $\sim 20 \%$ ). Total protein content of BAL was determined using bicinchoninic acid (Pierce Chemical Co., Rockford, IL). Total BAL cell count of the resuspended cell pellet was obtained by a counter (Coulter Electronics, Inc., Hialeah, FL) and BAL differential white cell count was done after cytocentrifugation.

Coagulation assays. BAL was exposed to normal pooled plasma (George King, Inc., Overland Park, KS) and the recalcification time in the presence of $8.3 \mathrm{mM} \mathrm{CaCl}_{2}$ was determined as previously described $(19,21)$. Interassay variation was $<6 \%$, as previously reported $(21)$ and BAL procoagulant activity was determined to be stable at $-70^{\circ} \mathrm{C}$ for at least $1 \mathrm{yr}$. All assays were performed in duplicate using the same lot of plasma. The recalcification times of BAL were converted to procoagulant unit equivalence, based upon the recalcification times generated by tissue factor standards, where $100,000 \mathrm{U}$ of procoagulant activity was defined as the recalcification time generated by $100 \mu \mathrm{l}$ of a $1-\mathrm{mg} /$ $\mathrm{ml}$ suspension of rabbit brain thromboplastin (American-Dade, Aquada, Puerto Rico).

To determine the activity attributable to the extrinsic pathway inhibitor, we used the three-stage coagulation assay described by Broze and Miletich (26). A standard curve was constructed using pooled normal human plasma and a linear relationship was observed between the log of the clotting time and the log of plasma concentration (0.1-8\% plasma). All BAL samples were undiluted and assayed in duplicate.

Amidolytic assay of factor Xa. Conversion of factor $\mathrm{X}$ to $\mathrm{Xa}$ by BAL was determined by an amidolytic assay performed in duplicate as previously described, with slight modifications (21). In this assay, $45 \mu \mathrm{l}$ of BAL was incubated with $30 \mu \mathrm{l}$ of $0.15 \mathrm{M} \mathrm{NaCl} 0.02 \mathrm{M}$ Tris at $\mathrm{pH} 7.4$ and $15 \mu \mathrm{l}$ of purified human factor $\mathrm{X}(10 \mathrm{U} / \mathrm{ml}$ [27]). This mixture was incubated at $37^{\circ} \mathrm{C}$ for up to $30 \mathrm{~min}$. Aliquots of $75 \mu \mathrm{l}$ were added to a spectrophotometer cuvette containing $25 \mu \mathrm{l}$ of $4 \mathrm{mM}$ benzoyl-isoleucyl-glutamyl-glycyl-arginine-p-nitroanilide (S-2222, Kabi Group Inc., Greenwich, CT) and $200 \mu \mathrm{l}$ of $50 \mathrm{mM}$ Tris, $175 \mathrm{mM} \mathrm{NaCl}$, and 7.5 mM EDTA, pH 8.4. Determination of factor Xa formed was based on the initial rate of increased absorbance at $405 \mathrm{~nm}$ using a response spectrophotometer (Gilford Instrument Laboratories, Inc., Oberlin, $\mathrm{OH})$. The picomoles of factor $\mathbf{X}$ hydrolyzed per minute per milliliter of BAL was calculated based on the initial rate of increase of absorbance generated by known concentrations of factor Xa (21).

Fibrin plate assay. Plasminogen activator (PA) activity and plasminogen-independent fibrinolytic activity of BAL was assayed on ${ }^{125} \mathrm{I}$ fibrin plates as previously described (28). BAL PA activity was found to be stable at $-70^{\circ} \mathrm{C}$ for over $1 \mathrm{yr}$. Briefly, plasminogen (purified as previously described [29]) and thrombin-free human fibrinogen
(Sigma Chemical Co., St. Louis, MO) containing a mixture of ${ }^{125} \mathrm{I}$-labeled fibrinogen (by the dilute chloramine-T method [27]) to a specific activity of $\sim 1.5 \mu \mathrm{Ci} / \mu \mathrm{g}$ and unlabeled fibrinogen was dried on 24-well flat-bottomed plates (No. 25820, Corning Glass Works, Corning, NY). Thrombin (Sigma Chemical Co.) solution $(0.2 \mathrm{ml}$ of $0.05 \mathrm{U} / \mathrm{ml})$ was added for $1 \mathrm{~h}$ at $37^{\circ} \mathrm{C}$ to convert fibrinogen to fibrin. Samples $(300 \mu \mathrm{l})$ were added to $300 \mu \mathrm{l}$ of $0.1 \mathrm{M}$ Tris- $\mathrm{HCl}, \mathrm{pH} 8.1$ plus $0.1 \%$ gelatin with or without $12 \mu \mathrm{g}$ of plasminogen per milliliter, and assayed in duplicate. Buffer blanks and trypsin (generating total releasable counts) samples were run on each plate. Plates were agitated at 50-100 rpm and $40 \mu \mathrm{l}$ were removed at $30 \mathrm{~min}, 1,2,4,6,9,12,24,31$, and $48 \mathrm{~h}$ and counted. The $48-\mathrm{h}$ time course was chosen to enhance the sensitivity of the assay required for the study of unconcentrated BAL samples. Fibrinolytic activity generated by BAL or urokinase standards (American Diagnostics, Inc., Greenwich, CT) was found to be sigmoidal and not linear over time and the PA activity of BAL was based upon the time at which $50 \%$ of releasable radioactivity was achieved. The PA activity in international units per milliliter (IU/ml) of each sample was calculated from the urokinase standard curve which had a sensitivity of 0.0049 $\mathrm{IU} / \mathrm{ml}$.

Fibrin gel autography. Fibrin gel autography was performed as described by Levin et al. (30). Briefly, prestained high molecular weight standards, BAL, or urokinase (u-PA) standards were subjected to SDS-10\% polyacrylamide gel electrophoresis (SDS-PAGE), and the gel was soaked in $0.1 \mathrm{M}$ sodium phosphate, $\mathrm{pH} 7.2$, with $2.5 \%$ Triton $\mathrm{X}-100$, blotted dry, and placed on top of a freshly prepared fibrin indicator gel. The indicator gel was allowed to develop at room temperature in a moist chamber, and then photographed.

Reverse fibrin gel autography. Reverse fibrin gel autography was performed as previously described (31). Samples were subjected to SDS-PAGE, and the gel was soaked in $2.5 \%$ Triton X-100 to neutralize the SDS and then placed over a fibrin-agar indicator plate containing $0.075 \mathrm{IU} / \mathrm{ml}$ of urokinase. Formation of opaque, lysis-resistant zones in the clear, lysed indicator gel indicated regions in the gel containing the PA inhibitor.

Antiplasmin activity. Antiplasmin activity was measured by mixing equal volumes $(325 \mu \mathrm{l})$ of $5 \mu \mathrm{g} / \mathrm{ml}$ plasmin (American Diagnostics, Inc., New York) diluted in normal saline with saline alone or BAL samples for $30 \mathrm{~min}$ at $37^{\circ} \mathrm{C}$. Residual fibrinolytic activity was determined by the ${ }^{125} \mathrm{I}$-fibrin plate assay described above.

Goat antibody to human $\alpha_{2}$-antiplasmin $\left(\alpha_{2} \mathrm{AP}\right)$ and control goat IgG (purchased from American Diagnostica) were bound to Affigel-10 beads (Bio-Rad Laboratories, Richmond, CA), according to the manufacturer's instructions at a ratio of $5 \mathrm{mg}$ of antibody per milliliter of resin. $\alpha_{2} \mathrm{AP}$ (American Diagnostica) was used to characterize the immobilized antibody. The beads were then used to adsorb BAL samples of antiplasmin activity. BAL $(325 \mu \mathrm{l})$ was incubated with either anti- $\alpha_{2} \mathrm{AP}$ or control beads bound to normal goat IgG 1:1 (vol/vol) for $1 \mathrm{~h}$ at room temperature. The beads were then centrifuged by a flash spin (Microfuge, Beckman Instruments, Inc., Fullerton, CA) and 325 $\mu \mathrm{l}$ of supernatant added to $325 \mu \mathrm{l}$ of plasmin standard $(1.25 \mu \mathrm{g} / \mathrm{ml})$. After incubation for $30 \mathrm{~min}$ at $37^{\circ} \mathrm{C}$, the resultant plasmin-mediated fibrinolytic activity was determined in the fibrin plate assay.

Measurement of plasminogen, $\alpha_{2} A P$, plasminogen activator inhibitor 2 (PAI-2) and antithrombin III (AT III). Double-antibody competitive equilibrium RIA were modified from those previously reported for human plasminogen and $\alpha_{2} \mathrm{AP}$ (32). Proteins were radioiodinated by the dilute chloramine-T method (27) to specific activities of 1.7-6.6 $\mu \mathrm{Ci} / \mu \mathrm{g}$. To $250 \mu \mathrm{l}$ of labeled protein $(0.5 \mathrm{nM})$ was added $250 \mu \mathrm{l}$ of competing human protein (for standard curve) or BAL fluid (diluted 1:4) and $250 \mu$ l of rabbit antibody diluted to give $\sim 30 \%$ binding of the iodinated ligand. After incubation at $4^{\circ} \mathrm{C}$ for $16-20 \mathrm{~h}, 500 \mu \mathrm{l}$ of goat anti-rabbit IgG (Pel-Freez Biologicals, Rogers, AR) was added and incubated at $4^{\circ} \mathrm{C}$ for $6 \mathrm{~h}$. The immunoprecipitates were collected by centrifugation at $2,000 \mathrm{~g}$ for $15 \mathrm{~min}$, and $500 \mu \mathrm{l}$ of supernatant was counted in a gamma counter. In control studies, the regression lines on semilogarithmic plots of the inhibition of ${ }^{125}$ I-protein binding to its specific antibody by normal BAL fluid were parallel to the competition 
curves observed for the purified protein and normal human plasma permitting an estimate of their concentration in BAL. The buffer used for the assay contained $50 \mathrm{mM}$ Tris- $\mathrm{HCl}(\mathrm{pH} 8.0), 25 \mathrm{mM} \mathrm{NaCl}, 10$ $\mathrm{mM}$ benzamidine, $1 \mathrm{mM}$ phenylmethylsulfonyl-fluoride, $5 \mathrm{U} / \mathrm{ml}$ aprotinin, $0.75 \%$ normal rabbit serum, and $0.02 \% \mathrm{NaN}_{3}$. Rabbit antibodies to human plasminogen and $\alpha_{2} \mathrm{AP}$ were generously provided by Drs. Edward F. Plow and Lindsey A. Miles (Research Institute of Scripps Clinic).

An RIA for PAI-2 was carried out according to Kruithof et al. (32). Dr. Kruithof (Laboratoire Centrale d'Hématologie, Lausanne, Switzerland) was kind enough to supply us with purified PAI-2, as well as the specific antiserum (33). PAI-2 was iodinated by the iodogen method (34). Standard curves for the RIA were constructed using PAI-2, and PAI-2 complexed to urokinase (u-PA). The standard curves generated by PAI-2 alone or PAI-2 complexed to u-PA (complete complex formation verified by SDS-PAGE and autoradiography of iodinated proteins) demonstrated that the RIA detected PAI-2 complexed to u-PA, as well as it detected free PAI-2 (35). The BAL samples were analyzed undiluted and diluted in $0.2 \mathrm{M} \mathrm{NaCl}, 10 \mathrm{mM}$ EDTA, 50 $\mathrm{mM}$ Tris-HCL, pH 7.4, 0.1\% BSA. Samples were incubated $4 \mathrm{~h}$ at room temperature with an equal volume of rabbit anti-human PAI-2 IgG, $(9 \mu \mathrm{g} / \mathrm{ml}) .50 \mu \mathrm{l}$ of ${ }^{125} \mathrm{I}-\mathrm{PAI}-2$ containing $2,100 \mathrm{cpm}$ was added, and the mixtures were incubated with rotation overnight at $4^{\circ} \mathrm{C}$. Antigen-antibody complexes were precipitated by a $30-\mathrm{min}$ incubation at room temperature with $100 \mu l$ of a $30 \%$ suspension of goat anti-rabbit IgG linked to agarose beads (Sigma Chemical Co.). The mixtures were centrifuged, the agarose beads were washed three times with $2 \mathrm{ml}$ of $0.15 \mathrm{M} \mathrm{NaCl}$, and radioactivity bound to the agarose beads was counted in a gamma counter (Beckman Instruments, Inc., Irvine, CA). In control experiments, BAL samples were supplemented with known amounts of purified PAI-2 and analyzed by RIA. Competition curves generated by these samples were parallel to the standard curve.

AT III was measured by RIA as we have previously reported (36). Factor Xa inhibiting activity of BAL was measured using the previously described amidolytic assay of factor $\mathrm{Xa}(21)$. Briefly, $100 \mathrm{ng}$ of factor $\mathrm{Xa}$ in $5.5 \mu \mathrm{l} 0.15 \mathrm{M} \mathrm{NaCl}, 0.02 \mathrm{M}$ Tris, $\mathrm{pH} 7.4$ (Tris-buffered saline [TBS]) was added to $150 \mu \mathrm{l}$ of TBS containing $1 \mathrm{mg} / \mathrm{ml} \mathrm{BSA}$ or BAL and the mixture was incubated at $37^{\circ} \mathrm{C}$ for $30 \mathrm{~min}$. Duplicate 75- $\mu \mathrm{l}$ aliquots were then removed for amidolytic analysis as described above. Amidolytic activity was expressed as nanogram per milliliter equivalents based on a factor Xa standard curve and residual activity after incubation with BAL was presented as a percentage of the activity obtained with the TBS-BSA blanks.

ELISA assay for plasminogen activator inhibitor 1 (PAI-1). Concentrations of PAI-1 were determined by an ELISA assay as follows: 96-well microtiter plates were coated with $10 \mu \mathrm{g} / \mathrm{ml}$ rabbit anti-human PAI-1 diluted in $50 \mathrm{mM}$ sodium borate, $\mathrm{pH} 9.0$, at $4^{\circ} \mathrm{C}$ overnight and washed with wash buffer PBS, $0.05 \%$ Tween $20,0.1 \%$ BSA. Samples or standards were diluted into PBS containing $0.05 \%$ Tween 20 and $1 \%$ BSA, and 100- $\mu$ l aliquots were incubated in the coated wells for $2 \mathrm{~h}$ at room temperature. The plates were washed with wash buffer, and 0.25 $\mu \mathrm{g} / \mathrm{ml}$ monoclonal antibody to PAI-1 (No. I105, Monozyme, Lyngby, Denmark) diluted into wash buffer containing $0.1 \%$ bovine globulin was added to the wells and incubated for $2 \mathrm{~h}$ at room temperature. After washing, the wells were incubated with a 1:2,000 dilution of horseradish peroxidase-conjugated rabbit anti-mouse IgG (Caltag, Burlingame, CA) for $2 \mathrm{~h}$, and washed again, and substrate was added. Plates were read after $45 \mathrm{~min}$ of incubation. This assay detects both free inhibitor and inhibitor in complex with tPA (data not shown). Standard curves for PAI-1 assays were determined by log-logit transformation of the binding reaction which gave a linear dose response in the range of $0.8-25 \mathrm{ng} / \mathrm{ml}$ PAI-1.

Detection of urokinase. Immunoblotting for u-PA was carried out as previously described (37). 55-kD u-PA, as well as goat anti-human u-PA antiserum was kindly supplied by Dr. Gene Murano of the Bureau of Biologics, Washington, DC (38). The sensitivity of the immunoblotting procedure was $0.1 \mathrm{ng} / \mathrm{ml}$. Using purified proteins, we demonstrated that $\mathrm{u}-\mathrm{PA}$ complexed to PAI-2 was recognized with the same sensitivity in immunoblots as was free u-PA. BAL samples supplemented with purified u-PA subsequently demonstrated this antigen in immunoblots.

A competition ELISA was also used to measure u-PA. 96-well microtiter plates were coated by an overnight $4^{\circ} \mathrm{C}$ incubation with 500 $\mathrm{ng} / \mathrm{ml}$ of Winkinase (Winthrop Laboratories, New York) in TBS, $\mathrm{pH}$. $8.5,0.1 \%$ BSA. All incubations were done in a humid chamber. Competition wells preadsorbed with $3 \%$ BSA in TBS had $2.2 \mu \mathrm{g} / \mathrm{ml}$ polyclonal goat anti-human urokinase IgG (Dr. Gene Murano) in TBS, $0.1 \%$ BSA, $0.1 \%$ Tween $20.55 \mu \mathrm{l}$ of the test sample or known amounts of urokinase were added to each well and incubated at $4^{\circ} \mathrm{C}$ with rocking. Wells were then washed four times with TBS, $0.1 \%$ Tween (TBSTween). Subsequent washes were done similarly. Unbound sites were blocked with 3\% BSA in TBS. Competition mixtures were transferred and incubated for $60 \mathrm{~min}$ at $37^{\circ} \mathrm{C}$. Bound anti-urokinase antibody was detected by serial additions of 1:2,000 biotinylated donkey antigoat IgG (Bethesda Research Laboratories, Gaithersburg, MD), 1:8,000 avidin-alkaline phosphatase conjugate (Sigma Chemical Co.), and the ELISA amplification system (Bethesda Research Laboratories) as per the manufacturers instructions. The absorbance at $490 \mathrm{~nm}$ was read with a Microtiter plate reader (Molecular Devices, Palo Alto, CA) and a standard curve was generated from each plate. The amount of urokinase in the test wells was calculated by reading off the curve. The lower limit of detection of the assay was $0.1 \mathrm{ng} / \mathrm{ml}$.

Characterization of plasminogen-related antigen in $B A L$. The IgG fraction of goat antibody to human plasminogen was bound to Affigel- 10 beads according to the manufacturer's instructions at a ratio of 3 $\mathrm{mg}$ of antibody per milliliter of resin. BAL was adsorbed by addition of an equivalent volume $(250 \mu \mathrm{l})$ of goat anti-human plasminogen IgGAffigel and mixed by rotation at room temperature for $1 \mathrm{~h}$. The beads were collected by centrifugation for $30 \mathrm{~s}$ using a Microfuge and washed once in normal saline. Bound protein was eluted by boiling the Affigel beads for $4 \mathrm{~min}$ in the $2 \%$ SDS, $1 \%$ glycerol, $62.5 \mathrm{mM}$ Tris- $\mathrm{HCl}, \mathrm{pH}$ 6.8. Supernatants were applied to $4 \%$ acrylamide stacking gels and run on $7 \%$ acrylamide resolving gels by the method of Laemmli (39). Electrophoretic transfer to nitrocellulose was performed in the buffer system of Towbin et al. (40) using a transfer cell (Bio-Rad Laboratories) with a recirculating water bath $\left(4^{\circ} \mathrm{C}\right)$ at $60 \mathrm{~V}$ for $90 \mathrm{~min}$. The nitrocellulose paper was "blocked" by incubation with $0.5 \mathrm{M} \mathrm{NaCl}, 0.01 \mathrm{M}$ Tris, $\mathrm{pH} 7.5,3 \%$ gelatin for $30 \mathrm{~min}$ at room temperature, then exposed to a 1:200 dilution of monospecific rabbit anti-human plasminogen overnight at $4^{\circ} \mathrm{C}$. After incubation of ${ }^{125} \mathrm{I}$ goat anti-rabbit IgG $(0.1$ $\mu \mathrm{g} / \mathrm{ml}$ ) for $3 \mathrm{~h}$ at room temperature, the nitrocellulose paper was washed extensively, air-dried, and then loaded into an intensifying Casette (Quanta III, Dupont Co, Wilmington, DE) with XAR-17 x-ray film (Eastman Kodak Co., Rochester, NY). The molecular weights of plasminogen species were determined by the relative migration of transferred prestained standards (Bio-Rad Laboratories).

Statistical analysis. Nonparametric analysis of BAL variables was used as these variables are not known to be normally distributed. Intergroup variation for BAL variables was first determined by Kruskal-Wallis one-way analysis of variance. Specific comparison of BAL variables between groups was done using the Mann-Whitney U-Wilcoxon rank sum $\mathrm{W}$ test. The data are presented as box graphs which show the medians (horizontal dashed lines), ranges of $50 \%$ of the data points (boxes), and the entire range of values. Outlying values are indicated as points falling $>1.5 \times$ the outermost values of the box.

\section{Results}

BAL total protein and cellular analysis. BAL total protein concentration was significantly increased in ARDS BAL compared with that of any of the control groups (Table II). BAL total white cells were elevated in patients with ARDS compared with those at risk for ARDS or normal healthy control individuals but not significantly differ from patients with ILD. However, ARDS BAL samples were characterized by a 
Table II. Cellular Analysis and Total Protein Content in BAL Fluid from Patients with ARDS, at Risk for ARDS, with ILD, and Normal Controls

\begin{tabular}{|c|c|c|c|c|c|c|c|c|c|}
\hline Group & $n$ & Total WBC & $P$ & Neutrophils & $P$ & Macrophages & $P$ & Total protein & $P$ \\
\hline & & $\times 10^{6}$ & & $\%$ & & $\%$ & & $m g / m l$ & \\
\hline ARDS & 14 & $21.5(7.1-165)$ & - & $65(12-88)$ & 一 & $32(10-86)$ & - & $0.525(0.08-1.60)$ & - \\
\hline At risk & 5 & $12.8(3.1-17.2)$ & 0.026 & $9(2-37)$ & 0.0023 & $84(60-93)$ & 0.0029 & $0.120(0.04-0.32)$ & 0.0057 \\
\hline ILD & 8 & $21.9(9.4-48.0)$ & 0.83 & $7(1-17)$ & 0.0003 & $84(57-97)$ & 0.0017 & $0.100(0.04-0.34)$ & 0.0010 \\
\hline Normal & 10 & $8.6(3.2-10.8)$ & 0.0013 & $1(0-6)$ & 0.0001 & $93(77-98.5)$ & 0.0004 & $0.090(0.02-0.18)$ & 0.0013 \\
\hline
\end{tabular}

Data are presented as median values with the minimum and maximum values of the range. Confidence limits vs. ARDS are indicated.

marked neutrophilic pleocytosis and reduction of the percentage of BAL macrophages compared with any of the control groups (Table II).

Procoagulant activity of $B A L$. The recalcification times (expressed as coagulation units/100 $\mu$ l of ARDS BAL; median $354 \mathrm{U}$ ) in normal pooled plasma were significantly shorter than those of BAL of patients at risk for ARDS (median 48.5 U, $P=0.0024$ ), patients with ILD (median $52.7 \mathrm{U}, P$ $=0.0077$ ) or normal healthy controls (median $14.0 \mathrm{U}, P$ $=0.0004)$. The median of recalcification times of BAL of patients with ILD was likewise shorter than that from normal control subjects $(P=0.01)$ but recalcification times of BAL of at-risk patients often overlapped the range of normal controls $(P=0.25)$.

We have previously reported that tissue factor associated with factor VII accounts for most of the procoagulant activity present in ARDS BAL as well as that of healthy individuals (21). We therefore compared levels of factor X-activating activity in BAL of patients with ARDS and each of the control groups in order to gauge the relative expression of procoagulant activity related to the extrinsic coagulation pathway. BAL factor X-activating activity was found to be increased in patients with ARDS [median $1.24 \mathrm{pmol} /(\mathrm{min} \cdot \mathrm{ml})$ ] compared with normal control individuals [median $0.21 \mathrm{pmol} /$ $(\mathrm{min} \cdot \mathrm{ml}), P=0.0003$ ] or patients with interstitial lung disease [median $0.38 \mathrm{pmoles} /(\mathrm{min} \cdot \mathrm{ml}), P=0.0033$ ]. Although a trend towards lower levels of factor $\mathrm{X}$-activating activity was present in BAL of patients at risk for ARDS [median 0.60 $\mathrm{pmol} /(\mathrm{min} \cdot \mathrm{ml})]$ the levels did not achieve a statistical significance $(P=0.069)$ vs ARDS BAL. We were unable to detect factor Xa activity in any BAL samples by amidolytic assay in the absence of supplemental factor $X$.

Levels of extrinsic pathway inhibitor (EPI) were likewise increased in ARDS BAL (median $0.68 \mathrm{ng} / \mathrm{ml}$ ) compared with patients at risk for the syndrome (median $0.17 \mathrm{ng} / \mathrm{ml}, P$ $=0.0146$ ) or normal healthy controls (median $0.18 \mathrm{ng} / \mathrm{ml}, P$ $=0.0013$ ). Increased levels of EPI activity were detected in some patients with ILD (median $0.61 \mathrm{ng} / \mathrm{ml}$ ), but did not significantly differ from levels in BAL of patients with ARDS $(P=0.59)$. Although the EPI was increased in ARDS, it is appeared to be insufficient in controlling the increased procoagulant activity attributable mainly to tissue factor associated with factor VII. In contrast, the EPI appeared to effectively control the procoagulant activity present in ILD.

Antigenic levels of AT III were significantly increased in ARDS BAL (median $236.7 \mathrm{ng} / \mathrm{ml}$ ) vs. normal controls (median $24.2 \mathrm{ng} / \mathrm{ml}, P=0.0020$ ) or patients with ILD (median 8.4 $\mathrm{ng} / \mathrm{ml}, P=0.0020)$ and levels measured in BAL of patients at risk for ARDS (median 161.3, $P=0.27$ ) did not significantly differ from those with ARDS. In contrast, the factor Xa-inhibiting activity of ARDS BAL was low and did not signifcantly differ from that determined for any of the control groups (data not shown). In patients with ARDS, BAL levels of AT III were significantly correlated with BAL total protein ( $r$ $=0.6933, P=0.0004$ ) suggesting that the increased levels of this inhibitor in ARDS BAL reflects the extravasation of plasma proteins into the alveolar space.

Characterization and quantitation of the fibrinolytic activity present in $B A L$. As shown in Fig. 1, levels of fibrinolytic activity in ARDS BAL were significantly depressed compared

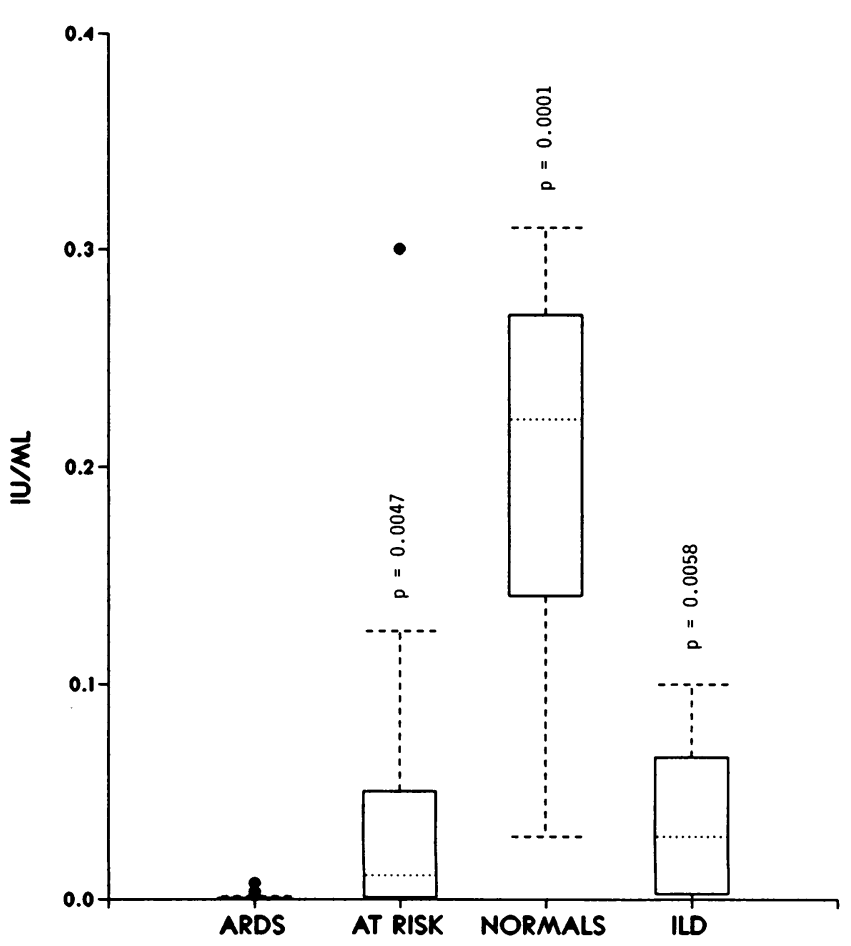

Figure 1. Fibrinolytic activity present in BAL from normal individuals and patients with ARDS, at risk for ARDS, or those with ILD. Fibrinolysis, determined by fibrin plate assay, is expressed as international units per milliliter relative to urokinase standards and is shown in a box plot format. Open boxes represent the field containing $50 \%$ of the values and contain the median (dotted lines). (Dashed lines) Range of values; (•) outlying values. Confidence limits vs. ARDS are shown. 
with levels in patients at risk for ARDS, those with ILD, or normal healthy controls. Fibrinolytic activity was invariably depressed in BAL of patients with ARDS; no fibrinolytic activity was found in BAL of 10 of 14 patients with ARDS and depressed levels were detectable in BAL of the remaining ARDS patients. Intermediate levels of fibrinolytic activity present in BAL of patients at risk for ARDS and those with ILD were likewise depressed compared with levels of normal healthy controls ( $P=0.0199$ and $P=0.0011$, respectively). The fibrinolytic activity present in BAL of normal control individuals as well as patients with ILD, those at risk for ARDS, or the four patients with ARDS in whom fibrinolytic activity was detectable, was found to be plasminogen dependent. No plasminogen independent fibrinolytic activity was detectable in any of these unconcentrated BAL samples by the ${ }^{125}$ I-fibrin plate assay.

The molecular weight analysis of the PA present in BAL was next investigated by fibrin gel enzymography. In normal BAL samples the major zone of fibrinolytic activity was found to comigrate with the 50,000 -mol wt urokinase (u-PA) standard, when the fibrin indicator gel contained plasminogen (Fig. $2 a$ ). The u-PA concentrations in all BAL samples were beneath the $0.1 \mathrm{ng} / \mathrm{ml}$ sensitivity of our ELISA assay and attempts to detect $\mathrm{u}-\mathrm{PA}$ in unconcentrated BAL samples by

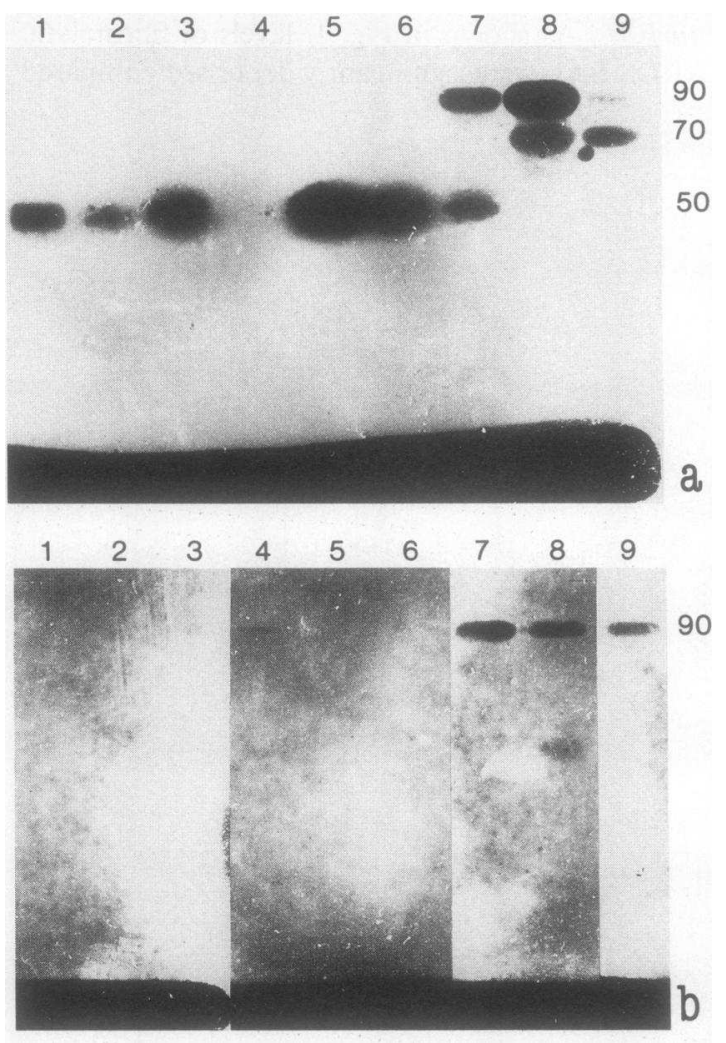

Figure 2. Fibrin gel enzymography of PA activity present in BAL from normal individuals and patients with ARDS or at risk for ARDS. Detection of PA activity was observed after electrophoresis on SDS-polyacrylamide gels, washing and overlaying on an agarose indicator gel containing fibrin in the presence $(a)$ or absence $(b)$ of plasminogen. Lanes 1-3, normal BAL; lanes 4-6, BAL from patients at risk for ARDS; lanes 7-9, BAL from ARDS patients. The molecular weights of the lysis zone (which were determined from parallel lanes containing prestained standards) are indicated.

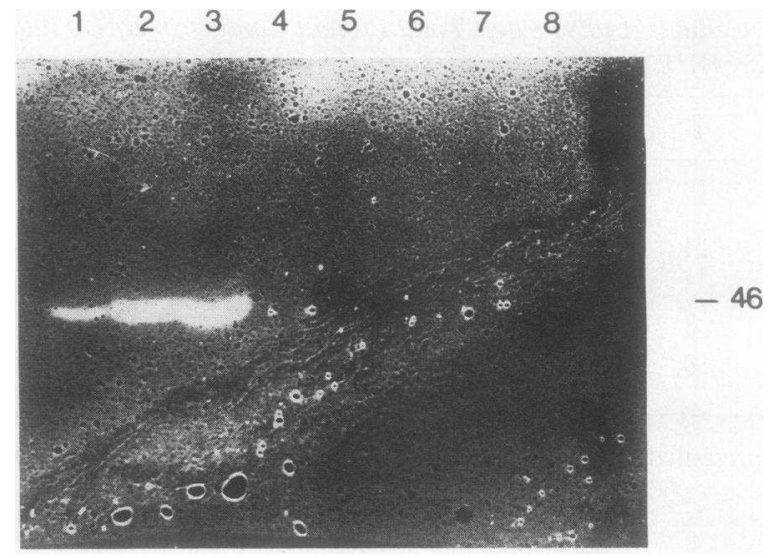

Figure 3. Reverse fibrin autography of BAL from patients with ARDS (lanes 1-3), at risk for ARDS (lanes 4-6), and normal individuals (lanes 7 and 8 ). The molecular weight of the lysis resistant zones was determined from prestained molecular weight standards electrophoresed in a parallel lane.

immunoblotting assays were also unsuccessful. However, the assumption of urokinase-like PA activity in BAL is based on the molecular weight and antibody neutralization observations reported by others $(23,41)$. By fibrin gel enzymography, the $50,000-\mathrm{mol} w t$ zone of fibrinolysis was either attenuated or absent in ARDS BAL ( $n=13$ samples studied) in which fibrinolytic activity was found to be depressed in the ${ }^{125} \mathrm{I}$-fibrin plate assay. This activity was, by contrast, detectable by enzymography in BAL of patients at risk for ARDS $(n=5)$, those with ILD $(n=4)$, and normal controls $(n=7)$. (Fig. $2 a$ ). Lytic zones of higher molecular weight were generated by ARDS BAL and corresponded to 90,000 and $70,000 \mathrm{~mol} \mathrm{wt} \mathrm{(Fig.} 2$ a). When plasminogen was deleted from the enzymography plates, fibrinolysis was absent at the 50,000- and/or 70,000mol wt zones in all BAL samples (Fig. 2 b). Thus, these activities were plasminogen dependent and suggest that the 70,000 mol wt form was attributable to urokinase-like PA bound to an inhibitor, as may be detected in this assay system (42). The $90,000-\mathrm{mol}$ wt zone persisted in the absence of plasminogen indicating the presence of plasminogen-independent fibrinolytic activity in these BAL samples. It appeared that the concentrations of this PA were too low to be detected in the fibrin plate assay or that this active molecular weight species may also represent an inactive enzyme-inhibitor complex under nondenaturing conditions.

Determination of (PAIs) was undertaken to further characterize these complexes as well as to document their presence in BAL. Control BAL samples and those from at-risk patients did not contain PAI activity using reverse fibrin autography consistent with the presence of relatively high levels of u-PA activity (Fig. 3). However, in patients with ARDS, lysis-resistant zones were identified at $46,000 \mathrm{~mol} \mathrm{wt}$, indicating the presence of PAI (Fig. 3).

Because the molecular weight of PAI activity was similar to that of PAI-1 secreted from Hep G2 cells (43), we performed antibody neutralization experiments to identify which PAI molecule was present in the BAL from ARDS patients. Samples of ARDS BAL were electrophoresed in parallel with conditioned medium from Hep G2 cells and the PAI activity was observed by reverse enzymography plates impregnated with 
either normal IgG or monospecific antibody to PAI-1. As shown in Fig. 4, the lysis-resistant zones identified in ARDS BAL as well as Hep G2 cells supernatants were inhibited in the presence of antibody to PAI-1. In addition, these samples were found to contain increased concentrations of PAI-1, as measured by ELISA assay (data not shown). Elevated levels of PAI-1 were variably found in BAL of 5 of 14 patients with ARDS (range 6.4-28.4 ng/ml) and one patient at risk for ARDS $(6.4 \mathrm{ng} / \mathrm{ml})$. Increased PAI-1 antigens in these BAL fluids paralleled increased PAI activity by reverse fibrin autography (Figs. 3 and 4). Conversely, BAL lacking detectable antigenic PAI-1 had no detectable PAI activity which could be detected by reverse autography. Very low concentrations of PAI-2 were identified in two of the patients with ARDS and were not found in BAL of any of the other patient groups. The lack of demonstrable PAI-2 in all of these BAL samples was not due to the assay in that supplemental amounts of PAI-2 (10-100 ng) added to BAL samples lacking detectable antigen were quantitatively recovered (data not shown).

We next investigated whether the lack of fibrinolytic activity in ARDS BAL was attributable to insufficient quantities of plasminogen in these fluids. The concentration of plasminogen was significantly increased in BAL from patients with ARDS as compared with any of the control groups (Fig. 5). Whereas low concentrations of plasminogen were detected in BAL of normal controls and patients with ILD, BAL from patients at risk for ARDS contained higher levels of the proteins. Thus, sufficient substrate for the PA was available in the BAL of ARDS patients.

We next sought to determine the physical state of the plasminogen substrate which would be available to participate in fibrinolytic reactions in ARDS BAL. Plasminogen derivatives were isolated from BAL using immune absorption and the plasminogen-related proteins were separated by SDS-PAGE, transferred to nitrocellulose, and localized by immunoblotting (Fig. 6). The principal form of plasminogen in ARDS BAL was the Glu-1-plasminogen (92,000 mol wt). Activation of the native protein to Lys 77 -plasminogen $(83,000 \mathrm{~mol} \mathrm{wt})$ was not detected in the BAL samples but the A chain of plasmin (Lys

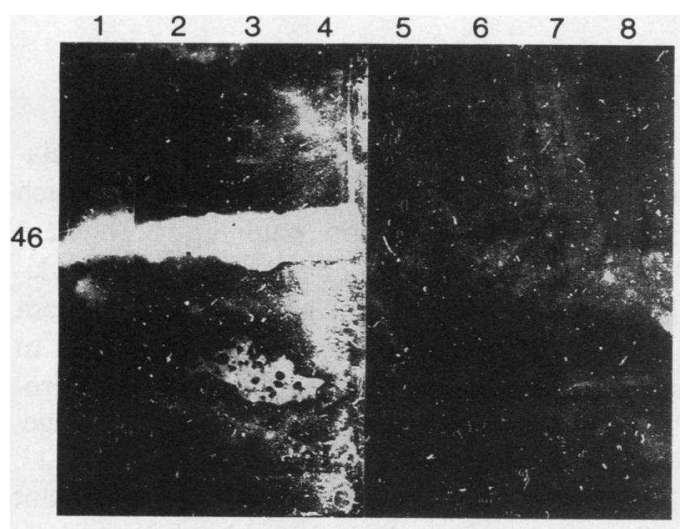

Figure 4. Antibody neutralization of PAI present in the BAL from patients with ARDS. Supernatants from Hep G2 cells (lanes 1 and 5) and BAL from ARDS patients (lanes 2-4 and 6-8) were electrophoresed and the PAI activity developed using reverse fibrin autography. The fibrin indicator gel contained either normal rabbit IgG (lanes 1-4) or rabbit anti-PAI-1 (lanes 5-8).

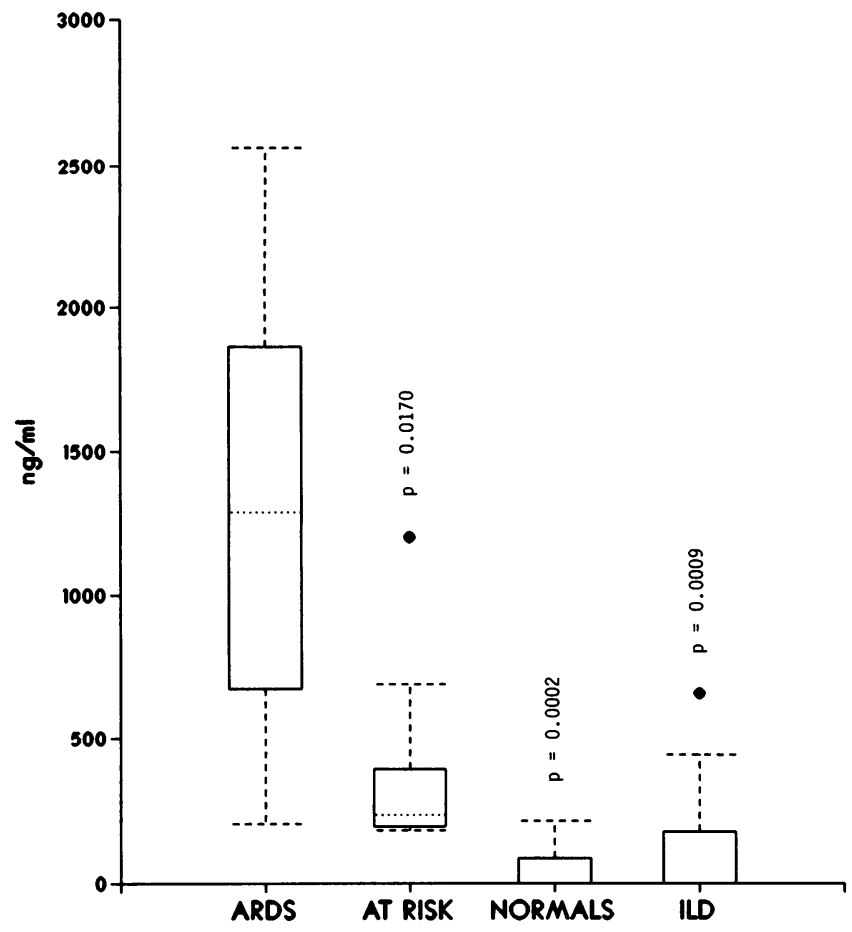

Figure 5. Quantitation of the plasminogen concentration in BAL from normal individuals and patients with ARDS, at risk for ARDS, and those with ILD by RIA. Values are shown in the box plot format as discribed in Fig. 1. Confidence levels vs. ARDS are indicated.

77-Arg 560; 56,000 mol wt) was detectable in ARDS BAL samples. BAL of normal individuals, patients at risk for ARDS, and patients with ILD likewise were found to contain Glu-1 plasminogen. In the ARDS as well as control BAL, higher molecular weight immunoreactive species were observed, and may represent plasmin-inhibitor complexes.

To determine if inhibition of generated plasmin could contribute to the depressed fibrinolytic activity associated with

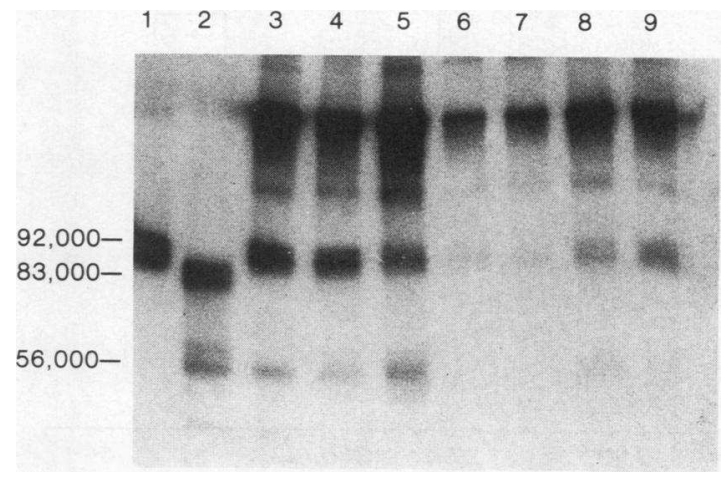

Figure 6. Autoradiogram of an immunoblot analysis of plasminogenrelated molecules in ARDS and control BAL. Proteins obtained by goat anti-human plasminogen-Affigel adsorption of BAL were separated by SDS-PAGE and localized using rabbit anti-human plasminogen and ${ }^{125} \mathrm{I}$-goat anti-rabbit IgG. Lane $1,100 \mathrm{ng}$ of purified Gluplasminogen; lane $2,100 \mathrm{ng}$ of activated plasminogen containing Lys-plasminogen $(83,000 \mathrm{~mol} \mathrm{wt})$ and plasmin $(56,000 \mathrm{~mol}$ wt A chain); lanes 3-5, ARDS BAL; lanes 6 and 7, BAL from normal controls; lane 8, patient at risk for ARDS; lane 9, patient with ILD. 
ARDS, we incubated BAL from ARDS patients with purified plasmin at concentrations predetermined to exceed the highest levels of PA-derived plasmin activity present in BAL of normal healthy control individuals. Nearly all of the fibrinolytic activity generated by 2.5 and $5 \mu \mathrm{g} / \mathrm{ml}$ plasmin standards in the ${ }^{125}$ I-fibrin plate assay was attenuated (mean $74.1 \%$ and $82.7 \%$ inhibition, respectively) by the addition of BAL samples ( $n$ =6) from patients with ARDS, indicating the presence of an active inhibitor of plasmin (data not shown). In comparative experiments, equal volumes of $1.25 \mu \mathrm{g} / \mathrm{ml}$ of plasmin and normal saline or BAL from each of the four groups were incubated for $30 \mathrm{~min}$ at $37^{\circ} \mathrm{C}$ and the residual plasmin activity measured by the fibrin plate assay. As shown in Fig. 7, little antiplasmin activity was identified in normal control BAL. Somewhat increased antiplasmin activity was present in BAL of patients at risk for ARDS (median $0.500 \mathrm{IU} / \mathrm{ml}, P=0.67$ ) and those with ILD (median $0.507 \mathrm{IU} / \mathrm{ml}, P=0.20$ ), relative to normals (Fig. 7). The antiplasmin activity of ARDS BAL was significantly increased ( 10-fold greater) compared to any of the control groups.

To characterize the antiplasmin activity contributing to the depressed fibrinolytic activity in BAL of patients with ARDS, we absorbed three BAL samples which contained no detectable fibrinolytic activity with antibody to $\alpha_{2} \mathrm{AP}$ or control IgG immobilized to Affigel-10 beads. The absorbed samples were then tested for their ability to neutralize $1.25 \mu \mathrm{g}$ of plasmin in

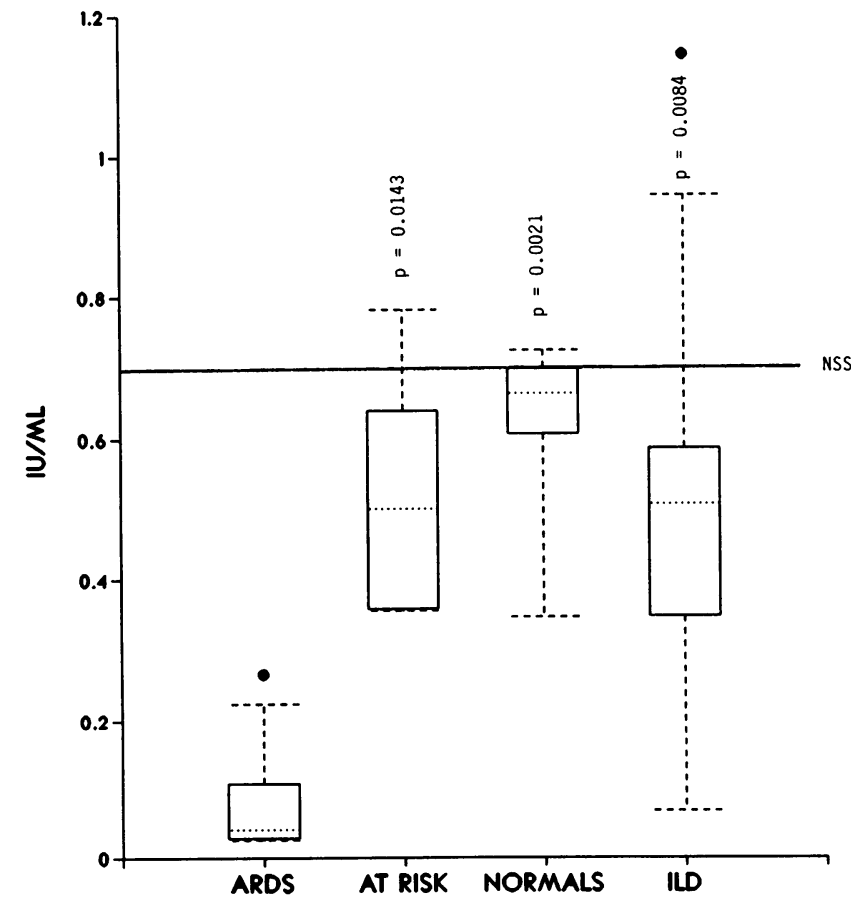

Figure 7. Inhibition of plasmin-mediated fibrinolysis by BAL. Equal volumes of plasmin $(1.25 \mu \mathrm{g} / \mathrm{ml})$ and normal saline $(N S S)$ or BAL from normal individuals or patients with ARDS, at risk for ARDS, or ILD were mixed and incubated at $37^{\circ} \mathrm{C}$ for $30 \mathrm{~min}$. The residual fibrinolytic activity (international units per milliliter) was measured in the fibrin plate assay. The bold horizontal line indicates the fibrinolytic activity after incubation with NSS. Values are presented in the box plot format as defined in Fig. 1. Confidence levels vs. ARDS are indicated.
Table III. Adsorption of Antiplasmin Activity from ARDS BAL by Immobilized Antibody to $\alpha_{2} A P$

\begin{tabular}{llcc}
\hline Sample & \multicolumn{1}{c}{ Antibody } & $\begin{array}{c}\text { Fibrinolytic } \\
\text { activity }\end{array}$ & $\begin{array}{c}\text { Residual } \\
\text { inhibition }\end{array}$ \\
\hline \multirow{3}{*}{ NSS } & & $I U / m l$ & $\%$ \\
ARDS 7 & + Control IgG & 0.3415 & - \\
& $+\alpha_{2}$ AP IgG & 0.0063 & 98.2 \\
ARDS 10 & + Control IgG & 0.1648 & 51.7 \\
& $+\alpha_{2}$ AP IgG & 0.0230 & 93.3 \\
ARDS 12 & + Control IgG & 0.0690 & 46.7 \\
& $+\alpha_{2}$ AP IgG & 0.1043 & 79.8 \\
& & & 69.5 \\
\hline
\end{tabular}

Equal volumes of ARDS BAL and either control goat IgG or the IgG fraction of goat antibody to human $\alpha_{2} \mathrm{AP}$ bound to Affi-Gel beads were incubated for $1 \mathrm{~h}$ at $37^{\circ} \mathrm{C}$. Aliquots were removed and mixed with a $1.25 \mu \mathrm{g} / \mathrm{ml}$ plasmin standard, after which fibrinolytic activity was determined in the fibrin plate assay. NSS, normal saline, which was the negative control incubated with the plasmin standard.

* Percent residual inhibition $=\left(I U_{N S S}-I_{\mathrm{BAL}}\right) / \mathrm{IU}_{\mathrm{NSS}} \times 100$.

the standard ${ }^{125}$ I-fibrin plate assay. As shown in Table III, inhibition of plasmin-mediated fibrinolytic activity could be partially reversed by absorption with antibody to $\alpha_{2} \mathrm{AP}$ but not control IgG. BAL samples $(n=6)$ were further diluted in normal saline but $\alpha_{2}$ AP activity could be only partially absorbed from four of the six samples while absorption was nearly complete in two samples (data not shown). To support the hypothesis of increased $\alpha_{2} \mathrm{AP}$ in ARDS BAL, we next determined the antigenic concentration by RIA (Fig. 8). $\alpha_{2} \mathrm{AP}$ was undetectable in BAL samples of patients with ILD or normal healthy controls and was detected in two patients at risk for ARDS. In contrast, elevations of $\alpha_{2} \mathrm{AP}$ were seen in the ARDS BAL. In patients with ARDS, BAL antiplasmin activity did not correlate with concentrations of $\alpha_{2} \mathrm{AP}(r=0.2, P$ $=0.4$ ), further suggesting that other plasmin inhibitors may contribute to the observed plasmin inhibitory activity in ARDS BAL. These data demonstrate that $\alpha_{2} \mathrm{AP}$ is, in part, responsible for the antiplasmin activity present in $\mathrm{BAL}$ of patients with ARDS.

\section{Discussion}

Tissue fibrin deposition represents the net effect of coagulation, which promotes fibrin formation, and fibrinolysis, which promotes fibrin dissolution. In previous studies, procoagulant activity attributable to components of the extrinsic coagulation pathway has been described in the alveolar compartment of man and experimental animals $(2,19,21,23,43-48)$. In addition, fibrinolytic activity attributable to urokinase or urokinase-like PA has been described in BAL and macrophages from the lower respiratory tract of humans and animals (23, $41,49,50)$. Under normal circumstances, little procoagulant activity $(21,47,48)$ and relatively high levels of fibrinolytic activity $(23,41)$ due to urokinase-like PA are found in human BAL. Normally then, extravascular fibrin is not detected in the lung (3). Conversely, acute lung injury is usually accompanied by extensive extravascular fibrin deposition $(1,3,4)$. Tissue fibrin deposition with prominent alveolar distribution is a his- 


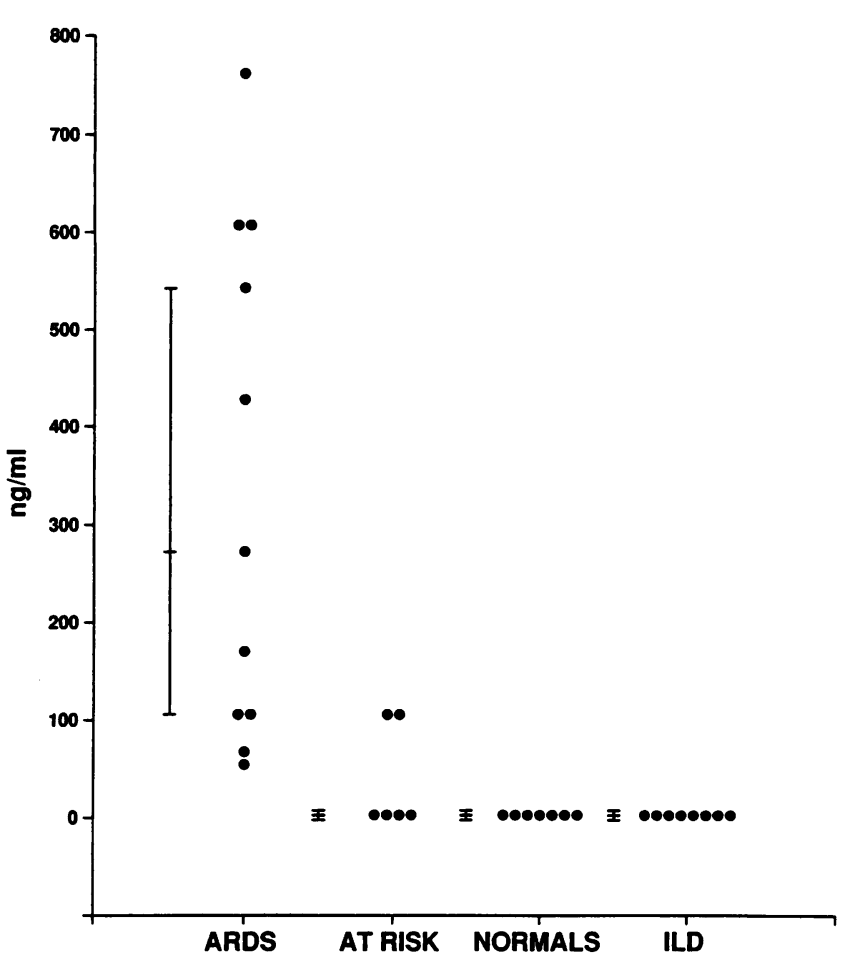

Figure 8. Concentrations of $\alpha_{2} \mathrm{AP}$ are shown in a dot plot. Immediately to the left of the dots, the horizontal line indicates the median value and the vertical line represents the range of $50 \%$ of the data around the median.

tologic hallmark of ARDS (3), and can be a prominent feature of the ILD and pneumonitides $(1,2)$. These observations suggest that the normal homeostasis of coagulation and fibrinolytic processes is disturbed in human lung injury and that conditions that promote fibrin deposition are established in the alveolar compartment.

In this study, we found that the balance of BAL procoagulant and fibrinolytic activities was most disrupted in patients with ARDS, as assessed by depression of fibrinolytic activity uniformly associated with increased procoagulant, antiplasmin, and PAI-1 activity in BAL. Although the potent inhibitor of the extrinsic coagulation pathway, EPI, and AT III locally increased, they are present in insufficient quantities to counter the enormous procoagulant potential of the ARDS BAL. Further, there is a discordance between AT III concentrations (elevated) and activity (normal) in ARDS BAL. Presumably, this inhibitor is complexed with factor $\mathrm{Xa}$ or thrombin and is unavailable to further regulate increases in these reactants generated by more proximal procoagulants. The aggregate effect of these abnormalities would be expected to promote alveolar fibrin deposition in ARDS. The severity of alveolitis was greatest in ARDS patients based upon multiple criteria including significant elevations of BAL total protein, marked BAL neutrophilia, and quantitatively worse indices of physiologic dysfunction including radiographic, oxygenation, and composite scores of disease severity.

Disruptions of these coagulation and fibrinolytic pathways were of lesser magnitude in patients at risk for ARDS and those with ILD. The uniform constellation of markedly increased BAL procoagulant activity with concurrent depression of fibrinolytic activity was inconsistently observed in individ- ual BAL samples from patients in these groups (data not shown). In patients with ILD, there was no significant correlation between abnormalities in BAL procoagulant or fibrinolytic activities and BAL total protein concentration, total white cell count, percentage neutrophils or lymphocytes, restrictive pulmonary function tests, or diagnosis (data not shown). BAL from patients with ILD and at risk for ARDS did not differ with respect to procoagulant, fibrinolytic, or antiplasmin activities. Procoagulant activity was increased in BAL of patients with ILD compared with normal controls ( $P$ $=0.0101$ ), but that of BAL of patients at risk for ARDS did not differ significantly from normal BAL $(P=0.25)$. Fibrinolytic activity was, however, depressed in both ILD and at risk BAL samples compared with that of normal control BAL ( $P$ $=0.0011$ and $P=0.0199$, respectively). Conditions that favor alveolar fibrin deposition therefore occur in the alveolar lining fluids of these patients as well. In particular, these observations confirm previous findings using BAL of patients with pulmonary fibrosis and sarcordosis (23) and suggest a putative mechanism by which alveolar fibrin forms in the interstitial diseases as previously described $(1,23)$.

Microvascular and interstitial injury which accompanies ARDS and other inflammatory lung disease permits extravasation of intravascular contents into the alveolar compartment. The bronchoalveolar compartment of the normal lung lacks factor X, prothrombin, and fibrinogen but contains factor VII, tissue factor, and factor V (48). Further, plasminogen, PAI-1, and $\alpha_{2} \mathrm{AP}$ are very low or absent. Our data indicate that such components of the circulating coagulation and fibrinolytic cascades may enter the alveoli and interact with the endogenous enzymes, substrates, or inhibitors to promote alveolar fibrin deposition. Alternatively, these reactants may be locally elaborated. For example, both tissue factor or PAI-1 could be released by injured endothelial cells or fibroblasts. It is probable that both processes, extravasation and abnormal elaboration of procoagulants and fibrinolytic inhibitors, contribute to locally disordered expression of procoagulant and fibrinolytic activities leading in a prothrombotic environment in the alveoli in ARDS.

Impaired fibrinolytic activity present in BAL of patients with ARDS was found to be due to effective inhibition of both plasmin and PA, rather than a lack of the PA substrate, plasminogen. Native Glu-plasminogen was easily detected in the BAL of ARDS patients, but little plasmin was observed. Sufficient antiplasmin activity was present in BAL to account for inhibition of all fibrinolytic activity generated by the PA found in normal BAL samples. Antiplasmin activity of ARDS BAL was found to be due in part to $\alpha_{2} \mathrm{AP} . \alpha_{2} \mathrm{AP}$ or PAI-1 was generally undetectable in BAL samples of control individuals. It is therefore likely that these circulating inhibitors gain entry to the alveolar space as a result of microvascular injury associated with ARDS.

The role of coagulation, fibrinolysis, and tissue fibrin deposition in the pathogenesis of ARDS is currently unclear. However, lung injury may be induced by the intravenous administration of procoagulants with or without concomitant inhibition of fibrinolysis (51-53), and catabolism of fibrinogen or fibrin may generate peptides which potentiate inflammatory reactions in the injured lung (4-9). Further, evidence has been accumulated that fibrin may influence lung repair after acute injury. In bleomycin-challenged marmosets, we found that 
parenchymal, primarily alveolar fibrin deposition was temporally associated with histologic and biochemical evidence of pulmonary fibrosis (19). In humans, persistent fibrin deposition has been found at foci of pulmonary fibrosis in two separate pathologic studies $(17,18)$. In normal wound healing, extravasated procoagulants interact with locally expressed tissue factor to promote fibrin formation which subsequently organizes to form mature scar tissue (54). If, by analogy, these processes occur in the severely injured human lung, then abnormalities of the procoagulant-fibrinolytic balance may figure importantly in the development of accelerated pulmonary fibrosis (or parenchymal fibrosis of lesser severity) which contributes to morbidity and mortality in ARDS.

In summary, we found that enhanced procoagulant activity is associated with severely impaired or absent fibrinolytic activity in BAL of patients with ARDS. Similar but less profound abnormalities may occur in patients at risk for ARDS and those with chronic pulmonary inflammation associated with ILD, predisposing these patients to alveolar fibrin deposition. Expression of increased procoagulant activity due mainly to tissue factor associated with factor VII occurs in ARDS BAL despite increases in AT III and EPI, whereas fibrinolytic activity is markedly depressed by a dual mechanism of inhibition of both plasmin and PA, effected, in part, by $\alpha_{2} \mathrm{AP}, \mathrm{PAI}-1$, and to a lesser extent, PAI-2. These concurrent abnormalities effectively reverse the normal balance of pathways of fibrin formation and dissolution in the lower respiratory tract of ARDS patients and establish conditions that promote the extensive alveolar fibrin deposition which is characteristically found in the lungs in ARDS. These observations most likely represent only part of the overall regulation of fibrin turnover in ARDS, as cell-cell interactions and cell surface assembly sites may assume important regulatory functions. However, the changes present in BAL reflect the net effects of soluble mediators released into the microenvironment of the injured lung in ARDS, presumably by several cell types that participate in the local inflammatory response. The changes in pathways of $\mathrm{fi}$ brin turnover indentified in ARDS BAL may be strongly inferred to influence alveolar fibrin deposition in that the exudative fluids that bathe and persist within the alveoli in ARDS promote fibrin deposition and retard its clearance.

\section{Acknowledgments}

The authors wish to thank Drs. Gene Murano, Lindsey A. Miles, E. K. O. Kruithof, and Edward F. Plow for their contributions. We wish to thank Dr. Jerry McLarty for his help with the statistical analyses. We also wish to thank Ms. Frankie Barnes and Sandy Carlson for help in preparation of this manuscript.

This work is supported by National Institutes of Health Clinical Investigator Award HL-01603, and grants HL-37770, HL-30244, HL-01870, and AI-20247; a grant from the American Heart Association, Texas Affiliate; and the Gina Sabatasse Research Grant Award. This work was done during the tenure of Dr. Fairs's Established Investigator Award from the American Heart Association with funds contributed by the Texas affiliate.

\section{References}

1. Jackson, L. K. 1982. Idiopathic pulmonary fibrosis. Clin. Chest Med. 3:579-592.

2. Sitrin, R. G., P. G. Brubaker, and J. Fanton. 1987. Tissue fibrin deposition during acute lung injury in rabbits and its relationship to local expression of procoagulants and fibrinolytic activities. Am. Rev. Respir. Dis. 135:930-936.

3. Bachofen, M., and E. F. Weibel. 1982. Structural alterations of lung parenchyma in the adult respiratory distress syndrome. Clin. Chest Med. 3:35-56.

4. Saldeen, T. 1976. The microembolism syndrome. Microvasc. Res. 11:227-259.

5. Sueishi, K., S. Nanno, and K. Tanaka. 1981. Permeability enhancing and chemotactic activities of lower molecular weight degradation products of human fibrinogen. Thromb. Haemostasis. 45:90-94.

6. Rowland, F. N., M. J. Donovan, P. T. Picciano, G. D. Wilner, and D. L. Kreutzer. 1984. Fibrin-mediated vascular injury: identification of fibrin peptides that mediate endothelial cell retraction. Am. J. Pathol. 117:418-428.

7. Dang, C. V., W. R. Bell, D. Kaiser, and A. Wong. 1985. Disorganization of cultured vascular endothelial cell monolayers by fibrinogen fragment D. Science (Wash. DC). 227:1487-1490.

8. Edgington, T. S., L. K. Curtiss, and E. F. Plow. 1985. A linkage between the hemostatic and immune systems embodies in the fibrinolytic release of lymphocyte suppressive peptides. J. Immunol. 134:471-477.

9. Senior, R. M., W. F. Skodgen, G. L. Griffen, and G. D. Wilner. 1986. Effects of fibrinogen derivatives upon the inflammatory response. J. Clin. Invest. 77:1014-1019.

10. Kaplan, A. P., M. Silverberg, J. T. Dunn, and B. Ghehebrehiwat. 1982. Interaction of the clotting, kinin forming, complement and fibrinolytic pathways in inflammation. NY Acad. Sci. 25-38.

11. Kaplan, A. P., and K. F. Austen. 1975. Activation and control mechanisms of Hageman factor dependent pathways of coagulation, fibrinolysis, and kinin generation and their contribution to the inflammatory response. J. Allerg. Clin. Immunol. 56:491-506.

12. Wachtfogel, Y. T., V. Kucich, H. L. James, C. F. Scott, M. Schapira, M. Zimmerman, A. B. Cohen, and R. W. Colman. 1983. Human plasma kallikrein releases neutrophil elastase during blood coagulation. J. Clin. Invest. 71:1672-1677.

13. Plow, E. F. 1982. Leukocyte elastase release during blood coagulation. J. Clin. Invest. 69:564-572.

14. Ciano, P. S., R. B. Colvin, and H. F. Dvorak. 1986. Macrophage migration in fibrin gel matrices. Lab. Invest. 54:62-70.

15. Colvin, R. B., P. I. Gardner, R. O. Robbin, E. L. Verderber, J. M. Lanigan, and M. W. Mosesson. 1979. Cell surface fibrinogen-fibrin receptors on cultured human fibroblasts. Lab. Invest. 41:464-472.

16. Grinnel, F., M. Feld, and D. Minter. 1980. Fibroblast adhesion to fibrinogen and fibrin: requirement for cold-insoluble globulin (plasma fibrinectin). Cell. 19:517-525.

17. Pratt, P. 1978. The Lung: Structure, Function and Disease. Williams \& Williams Co., Baltimore, MD. 45-47.

18. Spencer, H. 1977. Pathology of the Lung. 3rd edition. W. B. Saunders Co., Philadelphia, PA. 236-240.

19. Idell, S., K. Gonzalez, C. K. MacArthur, C. G. Gillies, P. N. Walsh, J. McLarty, and R. S. Thrall. 1987. Bronchoalveolar lavage procoagulant activity in bleomycin-induced lung injury in marmosets: characterization and relationship to fibrin deposition and fibrosis. $\mathrm{Am}$. Rev. Respir. Dis. 136:124-133.

20. Johanson, W. G., J. R. Holcomb, and J. J. Coalson. 1982. Experimental diffuse alveolar damage in baboons. Am. Rev. Respir. Dis. 126:142-151.

21. Idell, S., K. Gonzalez, H. Bradford, C. K. MacArthur, A. M. Fein, R. Maunder, J. G. N. Garcia, D. Griffith, J. Weiland, T. K. Martin, J. McLarty, D. S. Fair, P. N. Walsh, and R. W. Colman. 1987. Procoagulant activity in bronchoalveolar lavage in the adult respiratory distress syndrome: contribution of tissue factor associated with factor VII. Am. Rev. Respir. Dis. 136:1466-1474.

22. Idell, S., U. Kucich, A. M. Fein, F. Keuppers, H. L. James, P. N. Walsh, G. Weinbaum, R. W. Colman, and A. B. Cohen. 1985. Elastase releasing factors in bronchoalveolar lavage from patients with 
adult respiratory distress syndrome. Am. Rev. Respir. Dis. 132:10981105.

23. Chapman, H. A., C. L. Allen, and O. L. Stone. 1986. Abnormalities in pathways of alveolar fibrin turnover among patients with interstitial lung disease. Am. Rev. Respir. Dis. 133:437-443.

24. Weinberg, P. F., M. A. Matthay, R. O. Webster, K. V. Roshos, I. M. Goldstein, and J. F. Murray. 1984. Biologically active products of complement and acute lung injury in patients with the sepsis syndrome. Am. Rev. Respir. Dis. 130:791-796.

25. Baker, S. P., B. O'Neill, W. Haddon, and W. B. Long. 1974. The injury severity score: a method for describing patients with multiple injuries and evaluating emergency care. J. Trauma. 14:187-196.

26. Broze, G. J., Jr., and J. P. Miletich. 1987. Characterization of the inhibition of tissue factor in serum. Blood. 69:150-155.

27. Fair, D. S., E. F. Plow, and T. S. Edgington. 1979. Combined functional and immunological analysis of normal and abnormal human factor X. J. Clin. Invest. 64:884-894.

28. Idell, S., B. T. Peterson, K. K. Gonzalez, L. D. Gray, R. Bach, J. McLarty, and D. S. Fair. 1988. Local abnormalities of coagulation and fibrinolysis and alveolar fibrin deposition in sheep with oleic acid-induced lung injury. Am. Rev. Respir. Dis. 138:1282-1294.

29. Deutsch, D. G., and E. T. Mertz. 1980. Plasminogen: purification from human plasma by affinity chromatography. Science (Wash. DC). 170:1095-1097.

30. Levin, E. G., D. S. Fair, and D. J. Loskutoff. 1983. Human hepatoma cell line plasminogen activator. J. Lab. Clin. Med. 102:500-508.

31. Erickson, L. A., D. A. Lawrence, and D. J. Loskutoff. 1984. Reverse fibrin autography: a method to detect and partially characterize protease inhibitors after sodium dodecyl sulfate-polyacrylamide gel electrophoresis. Anal. Biochem. 137:454-463.

32. Kruithof, E. K. O., C. Tran-Thang, A. Guideinchet, J. Hawert, G. Nicoloso, C. Benton, H. Welti, and F. Bachmann. 1987. Fibrinolysis in pregnancy: a study of plasminogen activator inhibitors. Blood. 69:460-466.

33. Kruithof, E. K. O., J. D. Vassalli, W. D. Schleuning, R. J. Mattaliano, and F. Bachmann. 1986. Purification and characterization of plasminogen activator inhibitor from the histiocytic lymphoma cell line U-937. J. Biol. Chem. 261:11207-11213.

34. Fraker, P. J., and J. D. Speck, Jr. 1978. Protein and cell membrane iodination with a sparingly soluble chloramine 1,3,4,6-tetrachlor- 3a,6a-diphenylglycouril. Biochem. Biophys. Res. Commun. 80:849-857.

35. Schwartz, B. S., M. C. Monroe, and J. D. Bradshaw. 1989. Endotoxin induced production of plasminogen activator inhibitor by human monocytes is autonomous and can be inhibited by lipid $\mathrm{X}$. Blood. 73:2188-2195.

36. Fair, D. S., and B. R. Bahnak. 1984. Human hepatoma cells secrete single chain factor $\mathrm{X}$, prothrombin and antithrombin III. Blood. 64:194-204.

37. Schwartz, B. S., M. C. Monroe, and E. G. Levin. 1988. Increased release of plasminogen activator inhibitor type 2 accompanies the human mononuclear cell tissue factor response to lipopolysaccharide. Blood. 71:734-741.

38. Murano, G., D. Aronson, L. Williams, and L. Brown. 1980. The inhibition of high and low molecular weight urokinase in plasma. Blood. 55:430-436.
39. Laemmli, U. K. 1970. Cleavage of structural proteins during the assembly of the head of bacteriophage T4. Nature (Lond.). 227:680-685.

40. Towbin, H., T. Staekelin, and Jordan, Jr. 1979. Electrophoretic transfer of proteins from polyacrylamide gels to nitricellulose sheets: procedure and some applications. Proc. Natl. Acad. Sci. USA. 76:4350-4354.

41. Bowen, R. M., J. R. Hoidal, and R. D. Estensen. 1985. Urokinase-type plasminogen activator in alveolar macrophages and bronchoalveolar lavage fluid from normal and smoke exposed hamsters and humans. J. Lab. Clin. Med. 106:667-673.

42. Vassalli, J. D., J. W. Dazer, A. Wohlwend, and D. Belin. 1984. Concomittant secretion of prourokinase and of a plasminogen activator specific inhibitor by cultured human monocytes-macrophages. $J$. Exp. Med. 159:1653-68.

43. Springers, E. D., H. M. G. Princen, T. Kooistra, and V. W. M. Van Hinsbergh. 1985. Inhibition of plasminogen activators by conditioned medium from human hepatocytes and hepatoma cell line Hep G2. J. Lab. Clin. Med. 105:751-758.

44. McGee, M. P., and H. Rothberger. 1985. Tissue factor in bronchoalveolar lavage fluids evidence for an alveolar macrophage source. Am. Rev. Respir. Dis. 131:331-336.

45. Sitrin, R. G., H. B. Kaltrieder, M. H. J. Ansfield, and R. O. Webster. 1983. Procoagulant activity of rabbit alveolar macrophages. Am. Rev. Respir. Dis. 128:282-287.

46. Rothberger, H., M. P. McGee, and T. K. Lee. 1984. Tissue factor activity: a marker of alveolar macrophage maturation in rabbits. Effects of granutomatous pneumonitis. J. Clin. Invest. 73:1524-1531.

47. Chapman, H. A., C. L. Allen, O. L. Stone, and D. S. Fair. 1985. Human alveolar macrophages synthesize factor VII in vitro. Possible role in interstitial lung disease. J. Clin. Invest. 75:2030-2037.

48. Chapman, H. A., M. Stahl, C. L. Allen, R. Yee, and D. S. Fair. 1988. Characterization of the procoagulant activity within the bronchoalveolar compartment of normal human lung. Am. Rev. Respir. Dis. 137:1417-1425.

49. Chapman, H. A. Jr., Z. Vavrin, and O. L. Stone. 1984. Degradation of fibrin and elastin by human alveolar macrophages in vitro: characterization of a plasminogen activator and its role in matrix degre-degradation. J. Clin. Invest. 73:806-815.

50. Chapman, H. A., Z. Vavrin, and J. B. Hibbs, Jr. 1982. Macrophage fibrin fibrinolytic activity: two pathways of plasmin formation by intact cells and inhibitor of plasminogen activator. Cell. 28:653662.

51. Afors, K. E., C. Busch, S. Jokobsson, O. Lindquist, P. Malmberg, L. Rammer, and T. Saldeen. 1972. Pulmonary insufficiency following intravenous infusion of thrombin and AMCP (tranexamic acid) in the dog. Acta. Chir. Scand. 138:445-452.

52. Johnson, A., M. V. Tahamont, and A. B. Malik. 1983. Thrombin-induced vascular injury: role of fibrinogen and fibrinolysis. $\mathrm{Am}$. Rev. Respir. Dis. 128:38-44.

53. Malik, A. B. 1985. Mediators of pulmonary vascular injury and edema after thrombin in the pulmonary circulation and acute lung injury. S. I. Said, editor. Futura Publishing Co., Inc., Mount Kisco, NY. 429-454.

54. Dvorak, H. F. 1986. Tumors: wounds that do not heal. N. Engl. J. Med. 315:1650-1659. 